\title{
Padronização e determinação da fotoestabilidade do extrato de folhas de Pothomorphe umbellata L. Miq (pariparoba) e avaliação da inibição in vitro de metaloproteinases 2 e 9 na pele
}

\author{
Rebeca Leite Almeida*, Vanessa Vitoriano da Silva, Diogo Pineda Rivelli, Denise Varella Miranda, \\ Tania Cristina Higashi Sawada, Silvia Berlanga de Moraes Barros, Cristina Dislich Ropke
}

Departamento de Análises Clínicas e Toxicológicas, Faculdade de Ciências Farmacêuticas,

Universidade de São Paulo

*Correspondência:

R. L. Almeida

Departamento de Farmácia

Faculdade de Ciências Farmacêuticas

- USP

05508-950 - São Paulo, SP - Brasil

E-mail: almeida.rebeca@usp.br
A maioria das pesquisas realizadas até hoje sobre os efeitos benéficos da pariparoba (Pothomorphe umbellata L. Miq) foi feita com o extrato da raíz desta espécie, e o seu emprego em larga escala comprometeria a exploração sustentável deste insumo natural. Neste sentido o uso das folhas da pariparoba, ao invés de raízes pela indústria cosmética, não põe em risco a existência da espécie. Neste trabalho foi determinada a concentração de 4-nerolidilcatecol (4NC) de um extrato de folhas por metodologia analítica validada em nosso laboratório, cujo valor foi cerca de 30\% menor que no extrato de raiz, obtido da mesma maneira. Na avaliação de fotoestabilidade do extrato de folhas, uma solução de $0,25 \mathrm{mg} / \mathrm{mL}$ não apresentou alterações significativas do perfil espectroscópico após 2 horas de exposição à radiação UVB, demonstrando sua estabilidade. Metaloproteinases (MMPs) são endopeptidases dependentes de zinco, envolvidas na remodelagem da matriz extracelular (MEC), e importantes na formação das rugas típicas do fotoenvelhecimento cutâneo. Também avaliamos, por técnica de zimografia, a capacidade do extrato de folhas de P. umbellata de inibir a atividade de MMPs 2 e 9 in vitro de pele de camundongos sem pêlo. $O$ extrato de folhas $(0,1 \mathrm{mg} / \mathrm{mL})$ inibiu em $80 \%$ a atividade destas enzimas, conforme avaliação densitométrica.

\section{INTRODUÇÃO}

A pele encontra-se constantemente exposta a fatores ambientais, tais como radiação ultravioleta e visível, ozônio e radiação ionizante, que são fontes geradoras de radicais livres (Fuchs et al.,1989; Thiele et al.,1997). Depen- dendo da dose, tempo de exposição, comprimento de onda e região exposta, a radiação ultravioleta pode causar desde queimaduras na pele e envelhecimento cutâneo precoce até danos ao DNA celular cutâneo e câncer de pele (Scharfetter-Koshanek et al.,1997, Matsumura, Ananthaswamy, 2002). 
Metaloproteinases de matriz (MMPs) são enzimas de uma família de metaloendopeptidases, dependentes de zinco, que clivam componentes protéicos da matriz extracelular (MEC), moléculas de superfície e outras proteínas pericelulares que não pertencem a matriz (Egeblad \& Werb, 2002). A atividade destas enzimas é regulada por uma série de inibidores enzimáticos em níveis de transcrição gênica, sendo a classe de enzimas denominadas de inibidores de metaloproteinases (TIMPs - tissue inhibitors of MMPs) os mais importantes (Kerkelä et al, 2003; Snoek-Van Beurden, Von Den Hoff, 2005). A prevenção da degradação da MEC ocorre pelo equilíbrio entre MMPs e TIMPs.

As MMPs possuem um papel principal na remodelação do tecido conjuntivo que ocorre em muitos processos fisiológicos normais, como o crescimento e o desenvolvimento embrionário, cicatrização de feridas, crescimento ósseo e a involução uterina (Benaud et al., 1998; Sternlicht, Werb, 2001; Brummer et al., 2002; Egeblad, Werb, 2002; $\mathrm{Wu}$ et al, 2002). Além desses processos, a expressão anormal destas proteinases pode contribuir com uma variedade de processos patológicos caracterizados pela degradação da MEC, incluindo a artrite reumatóide, a aterosclerose e a invasão e metástase em tumores (Wu et al, 2002). MMPs 2 e 9 pertencem ao grupo das gelatinases, que possuem a capacidade de degradar a gelatina e denaturar o colágeno (Steffensen et al., 2001; Visse, Nagase, 2003). O colágeno tipo IV e tipo VII são componentes principais da membrana basal, primeira barreira para a invasão celular de tumores. A degradação da MEC por MMPs não apenas facilita a invasão tumoral mas, também, afeta o comportamento da célula tumoral e conduz a progressão do câncer (Itoh, Nagase, 2002).

Evidências demonstram que o dano causado pela exposição aguda e crônica à radiação ultravioleta é mediada por estresse oxidativo (Sander et al., 2002, 2004), que causa dano aos componentes celulares e altera o padrão de expressão gênica, levando a doenças de pele como o câncer, fototoxicidade e fotoenvelhecimento (ScharteffeterKochanek et al.,1997). Os antioxidantes de origem natural, aplicados topicamente ou administrados oralmente, apresentam uma perspectiva promissora de prevenção destas doenças por enriquecer o sistema de proteção cutâneo endógeno (Afaq et al., 2002, Saija et al., 1998; Fuchs,1998; Lopez-Torres et al.,1998).

A exposição repetida à luz solar resulta na indução de câncer de pele devido aos efeitos mutagênicos da radiação UV. $\mathrm{O}$ aumento rápido na incidência de neoplasias cutâneas pode ser atribuído quase que totalmente ao aumento da exposição à radiação UV solar. A formação de espécies reativas de oxigênio (EROS) devido a exposição à radiação UV, induz a expressão de MMPs (Rittié, Fisher, 2002). As EROS, além de indiretamente induzirem a liberação de MMPs, são capazes de inibir enzimas TIMPs, por uma reação oxidativa direta, contribuindo assim com o progresso de tumores e com o fotoenvelhecimento (Ma et al., 2001). Por estarem envolvidos no processo de invasão tumoral, os inibidores de MMPs são considerados um importante foco de pesquisa.

Estudos têm demonstrado que polifenóis naturais possuem efeitos significativos na prevenção do câncer possivelmente por suas propriedades antioxidantes (Agarwal et al.,1993).

Um estudo com Pothomophe umbellata, utilizando camundongos sem pêlo tratados topicamente com formulação gel contendo o extrato de raíz da planta e irradiados com UVB, demonstrou que o extrato é capaz de prevenir o envelhecimento cutâneo induzido pela exposição à radiação UV (Ropke et al., 2005). Parte da atividade antioxidante, quando avaliada in vitro foi atribuída à presença do 4-nerolidilcatecol (4-NC) (Figura 1) (Barros et al.,1996), molécula isolada dos extratos hexânicos de folhas e raízes de P. umbellata (Kijjoa,1980).

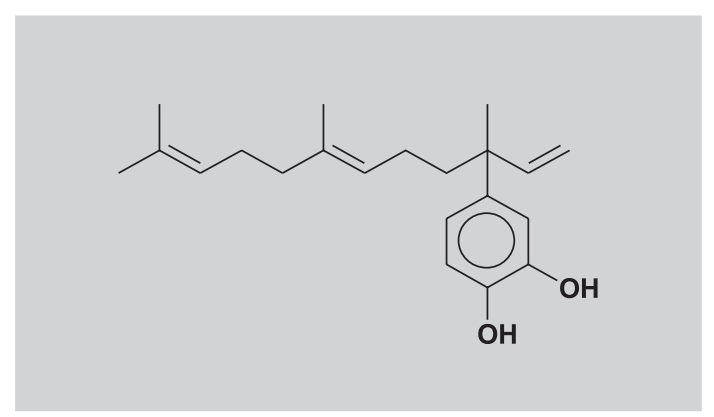

FIGURA 1- 4-nerolidilcatecol (Kijjoa et al.,1980)

O efeito expressivo do extrato de P. umbellata na prevenção de fotoenvelhecimento induzido na pele de camundongos sem pêlo expostos cronicamente à radiação UVB (Ropke, 2005), pode estar relacionado à atividade antioxidante do mesmo, o que poderia ter um efeito sobre as MMPs e seus inibidores. A espécie P. umbellata, em ensaios in vitro e in vivo foi capaz de inibir a atividade gelatinolítica de MMP-9 e MMP-2, em homogeneizados de pele de camundongos sem pêlo. Nos ensaios in vitro o efeito inibitório do extrato de P.umbellata foi muito maior que o do 4-NC isolado, o que sugere a presença de outras substâncias com atividade inibitória de MMPs no extrato (Ropke et al, 2006)

O estudo do efeito do extrato de P. umbellata e do 4-NC sobre a atividade das MMPs (MMP-2 e MMP-9) (Ropke et al., 2006) pode colaborar com a pesquisa sobre inibidores de MMPs e com o desenvolvimento de novos fármacos e/ou cosméticos para a prevenção de fotoenvelhecimento e 
fotocarcinogênese, fato importante em um país tropical como o Brasil, onde a incidência de radiação UV torna-se cada vez maior assim como o índice de câncer de pele. Da mesma forma, e devido a escassez de estudos, este trabalho com o extrato de folhas de $P$. umbellata traz uma contribuição importante para comunidade científica, já que o extrato de folhas é mais viável para utilização em grande escala, colaborando assim para a preservação e desenvolvimento sustentável da espécie.

Este trabalho teve por objetivos avaliar a fotoestabilidade do 4-NC presente no extrato seco de folhas de P. umbellata após 2 horas de exposição à radiação UVB e atividade inibitória de MMPs 2 e 9 in vitro do extrato de folha.

\section{MATERIAL E MÉTODOS}

\section{Obtenção do extrato}

O extrato hidroalcoólico de $P$. umbellata foi obtido pelo processo de percolação etanol:água (1:1) até o esgotamento da droga, segundo o processo da Farmacopéia dos Estados Unidos do Brasil e posteriormente concentrado à vácuo, sendo o resíduo aquoso liofilizado (Edwards do Brasil).

\section{Quantificação do 4-NC presente no extrato de folhas de Pothomorphe umbellata, empregando-se a técnica de cromatografia líquida de alta eficiência acoplada a um sistema de detecção eletroquímico}

O sistema cromatográfico foi composto de bomba Waters Model 510 injector 7161 Rheodyne dotado de loop de $20 \mu \mathrm{L}$, detector eletroquímico HP 1049 , constituído de eletrodo de trabalho de placas de carbono-vidro e um eletrodo de referência de estado sólido. O sinal produzido foi transmitido a um integrador SP4600 Termoseparation Products. A fase móvel utilizada foi metanol:água 90:10 (v/v), contendo $\mathrm{KCl} 2 \mathrm{mM}$ e $\mathrm{LiClO}_{4} 20 \mathrm{mM}$, com fluxo 1,0 mL/min. Coluna Supelcosil LC-8,3 $4 \mathrm{~m}, 75 \times 4,6 \mathrm{~mm}$ (Supelco, Bellefonte, PA, USA). O detector eletroquímico foi programado para potencial $=0,600 \mathrm{~V}$, polaridade $=$ oxidação, modo = amperometria. A padronização foi realizada segundo técnica já validada em nosso laboratório (Ropke, 2003).

Os resultados da quantificação foram comparados com o extrato seco de raíz de P. umbellata obtido nas mesmas condições.

\section{Fotoestabilidade do 4-NC presente no extrato seco de folhas de $P$. umbellata}

A fotoestabilidade foi determinada por meio da avaliação da concentração de 4-NC, por HPLC com detecção UV e espectrofotometria (Carlotti et al., 2002). Soluções do extrato de folha em metanol Uvasol ${ }^{\circledR}$ (Merk) e água (1:1) foram irradiadas em cubeta de quartzo sob uma lâmpada UVB Philips FS-40 por períodos de 30, 60, 90 e 120 minutos (doses de $206 \mathrm{~mJ} / \mathrm{cm}^{2}, 412 \mathrm{~mJ} / \mathrm{cm}^{2}, 618 \mathrm{~mJ} / \mathrm{cm}^{2}$, e 824 $\mathrm{mJ} / \mathrm{cm}^{2}$ respectivamente) à distância de $21 \mathrm{~cm}$. O sistema de HPLC foi composto por bomba Consta Metric 3200, detector espectrofotométrico Linear Instruments modelo 525 com comprimento de onda $282 \mathrm{~nm}$, coluna Phenomenex C18 $(3,9 \times 300 \mathrm{~mm}) 10 \mathrm{~mm}$. A fase móvel utilizada foi metanol:água (90:10) com fluxo $1,0 \mathrm{~mL} / \mathrm{min}$, sendo esta metodologia validada anteriormente em nosso laboratório.

Os espectros de absorção foram obtidos por um espectrofotômetro Hitashi U-3210 para cada um dos períodos de irradiação (Brisaert, Plaizier-Vercammen, 2000) em $282 \mathrm{~nm}$. Foi realizado em conjunto a avaliação do extrato seco de raíz de $P$. umbellata, preparado nas mesmas condições, contendo 7,68 \% de 4-NC.

\section{Determinação da inibição in vitro de MMP-2 e MMP- $9 \mathrm{em} 0,1 \mathrm{mg} / \mathrm{mL}$ de extrato de folhas de $P$. umbellata}

A pele dos camundongos sem pêlo com idade entre 10 e 12 semanas foi retirada da porção dorsal, separada e lavada com tampão Tris- $\mathrm{HCl}$ 0,05 M, 0,15 M NaCl, pH 7,4. Uma pequena quantidade $(0,1 \mathrm{~g})$ de tecido foi homogeneizada em 10 vezes o peso em volume ( $\mathrm{mL}$ ) de tampão Tris- $\mathrm{HCl}$ pH 7,4 contendo $0,2 \mathrm{M}$ de $\mathrm{NaCl}, 5 \mathrm{mM} \mathrm{CaCl}_{2}$ e $0,1 \%$ de Triton $\mathrm{X}$ 100 , e homogeneizado por 2 vezes consecutivas de 20 s em Ultra-Turax. Em seguida o homogeneizado foi submetido à centrifugação $8000 \mathrm{~g}$ durante $20 \mathrm{~min}$, à $4^{\circ} \mathrm{C}$, em centrífuga de mesa refrigerada, Eppendorf 5403. O sobrenadante foi empregado como amostra.

A concentração de proteína foi determinada pelo método de Lowry (1951), e as amostras contendo $20 \mu \mathrm{g}$ de proteína foram submetidas à eletroforese $(100 \mathrm{~V}, 1,5 \mathrm{~h}$, sistema Mini-Protean III BioRad), em gel de poliacrilamida $30 \%$ contendo $10 \%$ de dodecil sulfato de sódio (SDS), copolimerizado com $0,5 \%$ de gelatina. Ao final da corrida o gel foi cortado em tiras e lavado com Triton 2,5\% para remoção do SDS. As tiras foram incubadas a $37^{\circ} \mathrm{C}$ por $18 \mathrm{~h}$ em um tampão de incubação Tris- $\mathrm{HCl}$ 0,05M, $5 \mathrm{mM} \mathrm{CaCl}_{2}$, $5 \mu \mathrm{M} \mathrm{ZnCl}_{2}, \mathrm{pH} 8,0$ ou em tampão contendo $0,1 \mathrm{mg} / \mathrm{mL}$ de extrato de folhas de $P$. umbellata. Os géis foram corados com Coomassie Brilliant Blue por 30 minutos à temperatura ambiente e descorados com água contendo $10 \%$ de metanol e $10 \%$ de ácido acético. As gelatinases (MMP-2 e 9) aparecem como regiões não coradas de gelatina (Inomata et al., 2003). O gel foi digitalizado (450 d.p.i.) no Densitômetro de Calibração GS-700 BIO-RAD (Bloco 14 FCF) e as intensidades das bandas e pesos moleculares 
foram calculados utilizando o programa Molecular Analyzer (versão 1.4).

\section{RESULTADOS E DISCUSSÃO}

\section{Determinação da concentração de 4-NC no extrato seco de folhas de $P$. umbellata}

A concentração de 4-NC presente no extrato seco de folhas de $P$. umbellata demonstrou-se menor do que a quantidade presente no extrato seco de raíz preparado nas mesmas condições (Quadro 1). A análise foi realizada em triplicata, sendo o resultado apresentado a média dos valores obtidos.

QUADRO 1 - Concentração de 4-NC presentes no extrato seco de raiz e de folhas de P.umbellata solubilizado em etanol:água $(1: 1)$ na concentração de $0,25 \mathrm{mg} / \mathrm{mL}$ e porcentagem de 4-NC no extrato seco.

\begin{tabular}{lcc}
\hline Extrato seco & 4- NC $(\mathrm{mg} / \mathrm{mL})$ & $\begin{array}{c}\% 4-\mathrm{NC} \text { no } \\
\text { extrato seco }\end{array}$ \\
\hline raiz & $0,0192 \pm 0,0012$ & $7,68 \pm 0,08$ \\
folhas & $0,0102 \pm 0,0009$ & $4,08 \pm 0,03$ \\
\hline
\end{tabular}

$* \mathrm{p}<0,0001$ (Two Tailed $\mathrm{p}$, Unpaired $\mathrm{t}$ test)

\section{Fotoestabilidade do 4- NC no extrato de folhas e de raiz de $P$. umbellata}

A análise da concentração de 4-NC do extrato de folhas, comparada ao extrato de raiz de $P$. umbellata, avaliada durante o período de 2 horas de exposição à radiação UVB (Figura 2) demonstra sua estabilidade. Os valores são referentes à triplicata do experimento.

A pequena variação observada ao longo do período de irradiação, em relação à concentração provavelmente é devida à evaporação do solvente presente na cubeta sob irradiação, pois não houve diferença estatisticamente significativa entre os tempos de irradiação $(30,60,90,120$ minutos). Este resultado demonstra a estabilidade do 4-NC do extrato de folhas e raíz de P.umbellata conforme cromatogramas (Figuras 3 e 4), assim como observado para uma solução contendo 4-NC isolado do extrato de raiz, que não apresentou alterações no seu espectro de absorção e nem em sua concentração (Silva et al., 2005).

\section{Inibição in vitro de MMP-2 e MMP-9 em 0,1 mg/mL de extrato de folhas de $P$. umbellata}

O efeito inibitório da atividade gelatinolítica do homogeneizado de pele foi investigado por meio da adição do extrato de folhas de $P$. umbellata ao tampão de incubação.

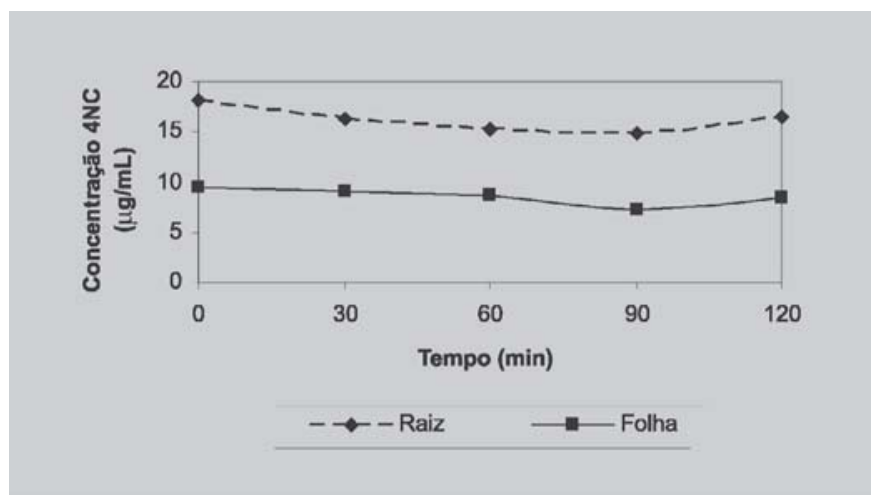

FIGURA 2 - Gráfico de fotoestabilidade do 4-NC no extrato de raiz e de folhas de $P$. umbellata em função do tempo de irradiação.

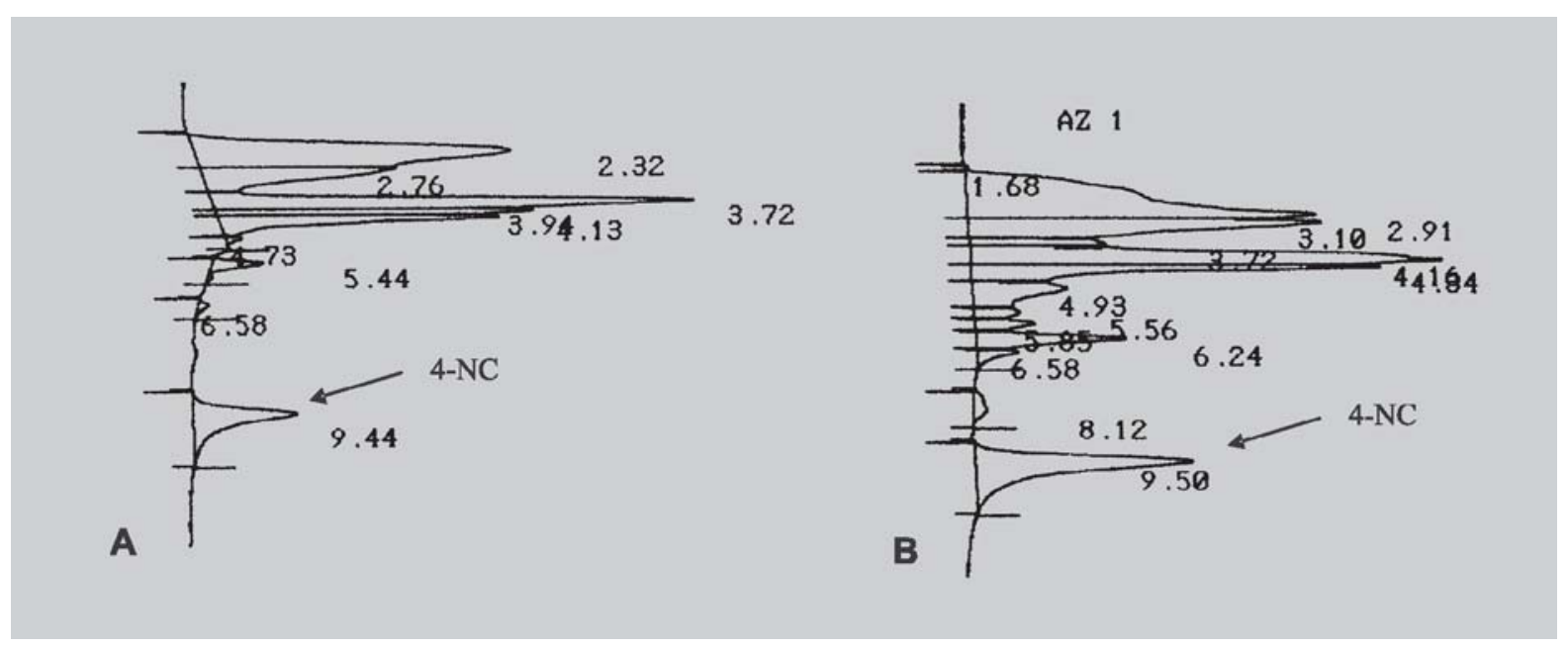

FIGURA 3 - Cromatogramas do extrato seco de folha (A) e de raiz (B) de P. umbellata $(0,25 \mathrm{mg} / \mathrm{mL})$ no tempo 0 minutos. 


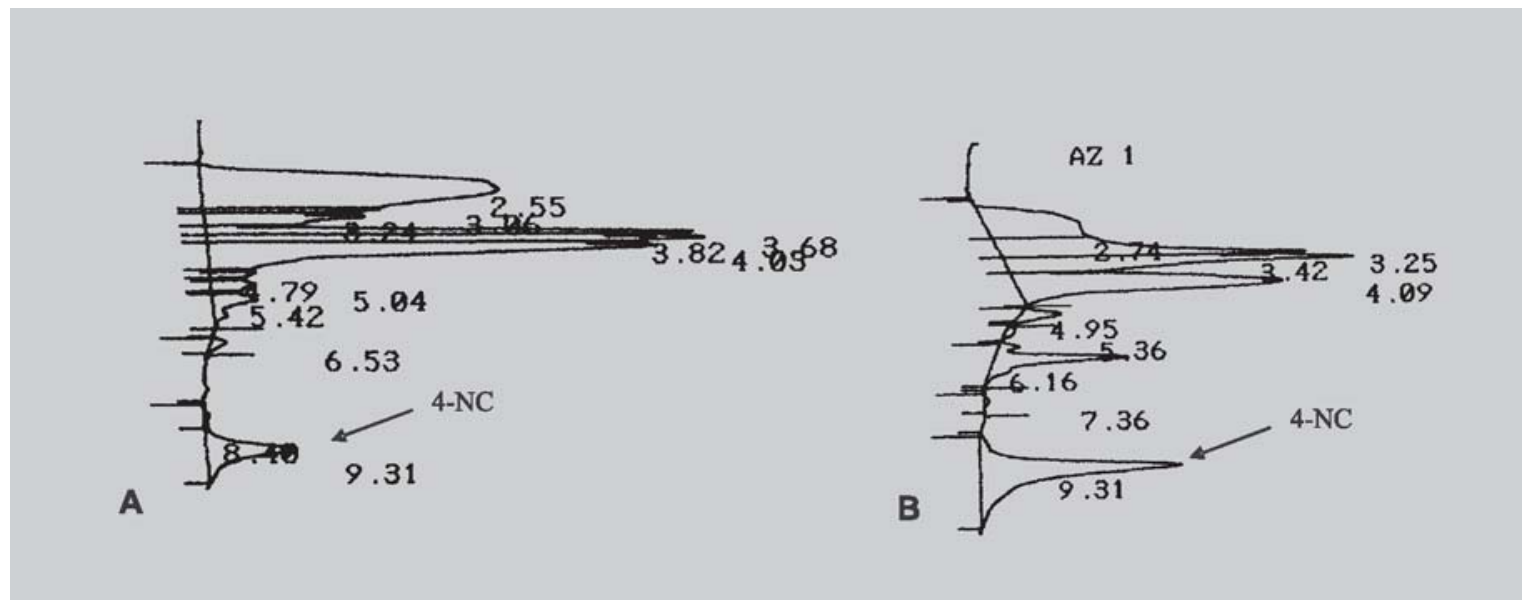

FIGURA 4 - Cromatogramas do extrato seco de folhas (A) e de raiz (B) de P. umbellata $(0,25 \mathrm{mg} / \mathrm{mL})$ no tempo de 120 minutos após exposição à radiação UVB.

O extrato de folhas de P. umbellata foi capaz de inibir a atividade das MMP-2 e 9 em relação ao gel controle, como demonstrado pela diminuição das bandas conforme Figura 5A. A atividade foi plotada por densitômetro (Figura 5B).

Grimm e colaboradores (2004) demonstraram que metabólitos M1 ( $\delta$-(3,4-dihidroxifenil)- $\gamma$-valerolactona) e M2 ( $\delta$-(3-metoxi-4-hidroxifenil)- $\gamma$-valerolactona) do picnogenol, composto antioxidante encontrado na casca de Pinus pinaster, foram capazes de inibir a atividade de MMP-1, MMP-2 e MMP-9. A semelhança estrutural entre M1 e 4-NC talvez possa explicar os resultados positivos de inibição de MMPs apresentados neste trabalho e em traba- lhos anteriores.

\section{CONCLUSÃO}

Conforme já publicado anteriormente (Moraes,1983) as folhas apresentam menor concentração do princípio ativo, 4-NC, em relação às raízes de $P$. umbellata no extrato seco. Os resultados deste trabalho podem explicar os ensaios de atividade antioxidantes realizados por Freitas (1999), que demonstraram uma atividade antioxidante menor do extrato de folhas em relação ao extrato de raiz.

O extrato de folhas apresentou atividade inibitória de

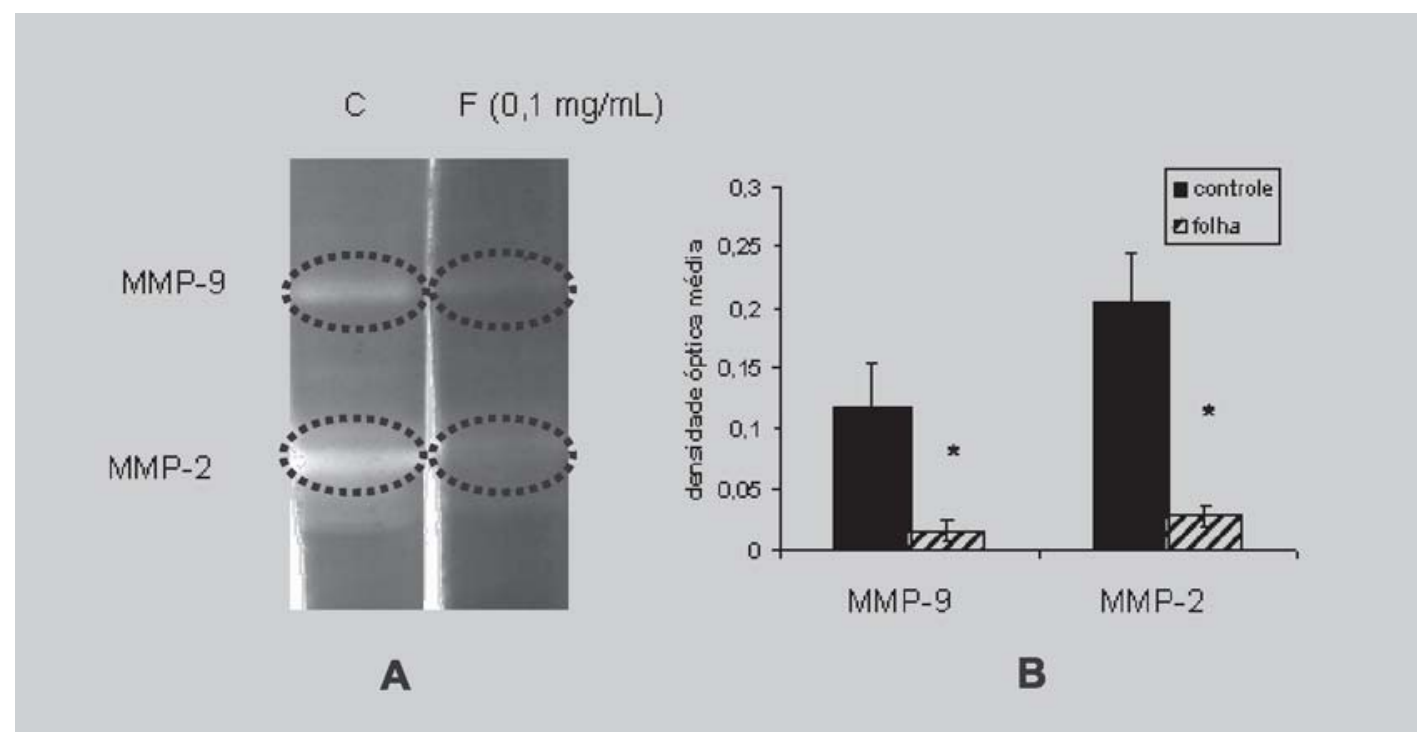

FIGURA 5 - A. Zimografias de homogeneizados de pele incubados com tampão (C) e $0,1 \mathrm{mg} / \mathrm{mL}$ de extrato de folhas de P. umbellata (F). As bandas claras representam a atividade enzimática de degradação do substrato e as bandas escuras mostram a inibição desta atividade. B. Os gráficos de barras representam as intensidades das bandas obtidas durante a análise densitométrica. Os dados representam as médias e desvios-padrão de três experimentos independentes. ${ }^{*} \mathrm{p}<0,05$. 
MMPs similar a obtida para o extrato de raiz na mesma concentração, dados presentes em um trabalho publicados por nosso grupo (Ropke et al., 2005). Neste ensaio in vitro o extrato foi capaz de inibir MMP-2 e MMP-9, mesmo possuindo menor concentração de 4-NC em relação ao extrato de raiz, provavelmente por causa da presença de outras substâncias inibidoras de MMPs presentes no extrato, assim como sugerido por outros ensaios no qual foi observado que o efeito inibitório do extrato de raiz de P.umbellata foi superior ao do 4-NC isolado (Ropke et al., 2006).

Os dados apresentados neste trabalho trazem informações importantes e inéditas, úteis para a utilização em grande escala do extrato de folhas de P.umbellata, colaborando assim para a preservação e desenvolvimento sustentável da espécie.

\section{AGRADECIMENTOS}

À FAPESP, pela bolsa de Iniciação Científica e auxílio.

\section{ABSTRACT \\ Standardization and determination of photostability of leaf extracts of Pothomorphe umbellata L. Miq (pariparoba) and evaluation of the inhibition in vitro of metalloproteinases 2 and 9 in skin}

Most researches that have been done until today about the beneficial effects of pariparoba (Pothomorphe umbellata L. Miq) have been done with root extract of this species, but the use in large scale would compromise the sustainable exploration of this natural resource. In this sense, the utilization of pariparoba leaves, substituting the roots, in the cosmetic industry does not put in risk the existence of the species. In this work the concentration of 4-nerolidylcathecol (4-NC) in leaf extract was determined by the analytical methodology validated in our laboratory. The concentration of 4-NC in leaf extract was around $30 \%$ less than that of root extract, obtained in the same way. Concerning the study of the photostability of a leaves extract solution containing 4-NC did not demonstrate meaningful alterations in the spectrometry profile after 2 hours of exposure under UVB radiation, showing its stability under this conditions. Metalloproteinases (MMPs) are endopeptidases that are zinc-dependent, involved in remodeling extracellular matrix (ECM), that are important in the appearance of typical photoaging wrinkles. In this work the capacity of leaf extract of $P$. umbellata to inhibit MMP-2 and 9 activities of hairless mouse skin in vitro by zymography gel was also evaluated. The leaf extract $(0,1$ $\mathrm{mg} / \mathrm{mL}$ ) inhibit in $80 \%$ activity of this enzymes, according to the densitometric zymography evaluation.

UNITERMS: Pothomorphe umbellata. Photostablility. Metalloproteinases

\section{REFERÊNCIAS BIBLIOGRÁFICAS}

AFAQ, F., ADHAMI, V.M., AHMAD, N., MUKHTAR, H. Botanical antioxidants for chemoprevention of photocarcinogenesis. Front. Biosci., v. 7, p. 784-792, 2002.

AGARWAL, R., KATIYAR, S.K., KHAN, S.G., MUKHTAR, H. Protection against ultraviolet B radiation-induced effects in the skin of SKH-1 hairless mice by a polyphenolic fraction isolated from green tea. Photochem. Photobiol., v. 58, n. 5, p. 695-700, 1993.

BARROS, S.B.M., TEIXEIRA, D.S., AZNAR, A.E., MOREIRA JUNIOR, J.A., ISHII, I., FREITAS, P.C.D. Antioxidant activity of ethanolic extracts of Pothomorphe umbellata L. Miq. Ciênc. Cult., v. 48, p. 114-116, 1996.

BRISAERT, M., PLAIZIER-VERCAMMEN, J. Investigation on the photostability of a tretinoin lotion and stabilization whit additives. Int. J. Pharm., v. 199, p. 4957, 2000.

BENAUD, C., DICKSON, R.B., THOMPSON, E.W. Roles of the matrix metalloproteinases in mammary gland development and cancer. Breast Cancer Res. Treat., v.50, n.2, p. 97-116, 1998.

BRUMMER, O., BOHMER, G., HOLLWITZ, B., FLEMMING, P., PETRY, K.U., KUHNLE, H. MMP-1 and MMP-2 in the cervix uteri in different steps of malignant transformation - an immunohistochemical study. Gynecol. Oncol., v.84, n.2, p.222-7, 2002.

CARLOTTI, M.E., ROSSATTO, V., GALLARATE, M. Vitamin A and vitamin A palmitate stability over time under UVA and UVB radiation. Int. J. Pharm., v.240, p. 85-94, 2002.

EGEBLAD, M.; WERB, Z. New functions for the matrix metalloproteinases in cancer progression. Nat. Rev. Cancer, v.2, p. 161-74, 2002. 
FREITAS, P.C.D. Atividade antioxidante de espécies medicinais da familia Piperaceae: Pothomorphe umbellata (L.) Miq. e Piper regnelli (Miq.). São Paulo, 2000. 115p. [Tese de Doutorado - Faculdade de Ciências Farmacêuticas - Universidade de São Paulo].

FUCHS, J., HUFLEJT, M.E., ROTHFUSS, L.M., WILSON, D.S., CARCAMO, G., PACKER, L. Acute effects of near ultraviolet and visible light on the cutaneous antioxidant defense system. Photochem. Photobiol., v.50, p. 739-744, 1989.

FUCHS, J. Potential and limitations of the natural antioxidants RRR-alphatocopherol, L-ascorbic acid and $\beta$-carotene in cutaneous photoprotection. Free Radic. Biol. Med., v.25, p.848-873, 1998.

GRIMM, T., SCHAFER, A., HOGGER, P. Antioxidant activity and inhibition of matrix metalloproteinases by metabolites of maritime pine bark extract (pycnogenol). Free Radic. Biol. Med., v. 36, p. 811-822, 2004.

INOMATA, S., MATSUNAGA, Y., AMANO, S., TAKADA, K., KOBAYASHI, K., TSUNENAGA, M., NISHIYAMA, T., KOHNO, Y., FUKUDA, M. Possible involvment of gelatinases in basement membrane damage and wrinkle formation in chronically ultraviolet $\beta$-exposed hairless mouse. J. Invest. Dermatol., v.120, p. 1-7, 2003.

ITOH,Y., NAGASE, H. Matrix metalloproteinases in cancer. Essays Biochem., v.38, p.21-36, 2002.

KERKELÄ, E., SAARIALHO-KERE, U. Matrix metalloproteinases in tumor progression: focus on basal and squamous cell skin cancer. Exp. Dermatol., v.12, p. 109-125, 2003.

KIJJOA, A. Estudo químico de algumas espécies da ordem magnoliales. São Paulo, 1980. 143 p. [Tese de Doutorado - Instituto de Química - Universidade de São Paulo].

LOPEZ-TORRES, M., THIELE, J.J., SHINDO, Y., HAN, D., PACKER, L. Topical application of $\alpha$-tocoferol modulates the antioxidant network and diminishes ultraviolet-induced oxidative damage in murine skin. $B r$. J. Dermatol., v.138, n.2, p. 207-215, 1998.

LOWRY, O.H., ROSEBROUGH, N.J., FARR, A.L., RANDALL, R. J. Protein measurement with the Folin phenol reagent. J. Biol. Chem., v. 193, p. 265-275, 1951.
MA, W., WLASHEK, M., TANCHEVA-POOR, I., SCHNEIDER, L.A., NADERI, L., RAZI-WOLF, Z., SCHÜLLER, J., SCHARFETTER-KOCHANEK, K. Chronological ageing and photoaging of the fibroblasts and the dermal connective tissue. Clin. Exp. Dermatol., v.26, p.592-599, 2001.

MATSUMURA, Y., ANANTHASWAMY, H.N. Short-term and long-term cellular and molecular events following UV irradiation of skin: implications for molecular medicine. Expert Rev. Mol. Med., v.2, p.1-22, 2002.

MORAES, M.S. Caracterização Farmacognóstica da droga e do extrato fluido de Pothomorphe umbellata $(L)$ Miq. São Paulo, 1983. 112p. [Dissertação de Mestrado Faculdade de Ciências Farmacêuticas - Universidade de São Paulo].

RITTIÉ, L., FISHER, G.F. UV-light-induced signal-cascades and skin aging. Aging Res. Rev., v.1, p.705-720, 2002

ROPKE, C.D., SILVA, V.V., KERA, C.Z., MIRANDA, D.V., ALMEIDA, R.L., SAWADA, T.C.H., BARROS, S.B.M. In vitro and in vivo Inhibition of Skin Matrix Metalloproteinases by Pothomorphe umbellata Root Extract . Photochem. Photobiol., v.82, p.439-442, 2006.

ROPKE, C.D., SAWADA, T.C., SILVA, V.V., MICHALANY, N.S., BARROS, S.B.M. Photoprotective effect of Pothomorphe umbellata root extract against ultraviolet radiation induced chronic skin damage in the hairless mouse. Clin. Exp. Dermatol., v.30, p. 272-276, 2005.

ROPKE, C.D., MEIRELLES, R.R., DA SILVA, V.V., SAWADA, T.C.H., BARROS, S.B.M. Pothomorphe umbellata extract prevents $\alpha$-tocopherol depletion after UV-irradiation. Photochem. Photobiol., v.78, n.5, p.436439, 2003.

SAIJA, A., TOMAINO, A., TROMBETTA, D., DE PASQUALE, A., UCCELLA, N., BARBUZZI, T., PAOLINO, D., BONINA, F. Influence of different penetration enhancers on in vitro skin permeation and in vivo photoprotective effect of flavonoids. Int. J. Pharm., v.175, p. 85-94, 1998.

SANDER, C.S., CHANG, H., HAMM, F., ELSNER, P., THIELE, J.J. Role of oxidative stress and the antioxidant network in cutaneous carcinogenesis. Int. J. Dermatol., v.43, p.326-335, 2004. 
SANDER, C.S., CHANG, H., SALZMANN, S., MULLER, C.S, EKANAYAKE-MUDIYANSELAGE，S., ELSNER, P., THIELE, J.J. Photoaging is associated with protein oxidation in human skin in vivo. J. Invest. Dermatol., v.118, p.618-25, 2002.

SILVA, V.V., ROPKE, C.D., ALMEIDA, R.L., MIRANDA, D.V., KERA, C.Z., RIVELLI, D.P., SAWADA, T.C.H., BARROS, S.B.M. Chemical stability and SPF determination of Pothomorphe umbellata extract gel and photostability of 4-nerolidylcathecol. Int.J. Pharm., v. 303, p. 125-135, 2005.

SNOEK-VAN BEURDEN, P.A.M., VON DEN HOFF, J. Zymographic techniques for the analysis of matrix metalloproteinases and their inhibitors. Bio Techniques: Review, v.38, n.1, p. 73-83, 2005.

STEFFENSEN, B., HAKKINEN, L., LARJAVA, H. Proteolytic enevts of wound-healing - coordinated interactions among matrix metalloproteinases (MMPs), integrins, and extracellular matrix molecules. Crit. Rev. Oral. Biol. Med., v. 12, p.373-398, 2001.
STERNLICHT, M.D., WERB, Z. How matrix metalloproteinases regulate cell behavior. Ann. Rev. Cell Dev. Biol., v.17, p. 463-516, 2001.

THIELE, J.J., TRABER, M.G., TSANG, K.G. In vivo exposure to ozone depletes vitamins $\mathrm{C}$ and $\mathrm{E}$ and incudes lipid peroxidation in epidermal layers of murine skin. Free Rad. Biol. Med., v.23, p. 385 -391, 1997.

VISSE, R., NAGASE, H. Matrix metalloproteinases and tissue inhibitors of metalloproteinases: structure, function, and biochemistry. Circ. Res., v.92, p.827-839, 2003.

WU, N., OPALENIK, S., LIU, J., JANSEN, E. D., GIRO, M. G., DAVIDSON, J. M. Real-time visualization of MMP13 promoter activity in transgenic mice. Matrix Biol., v.21, n.2, p. 149-61, 2002.

Recebido para publicação em 29 de janeiro de 2007. Aceito para publicação em 13 de novembro de 2007. 